\title{
Um coração futurista: a construção da sonoridade de Egberto Gismonti no início de sua trajetória (I969-I976)
}

[ A futuristic heart: the construction of Egberto Gismonti's sonority in the beginning of his carrier (I969-I976)

\section{Maria Beatriz Cyrino Moreira ${ }^{\mathrm{I}}$}

RESUMO - Este artigo tem como objetivo discutir o início da trajetória do músico brasileiro Egberto Gismonti a fim de desvendar procedimentos musicais que fizeram parte da construção de sua carreira ao longo dos anos I970, com especial atenção a sua produção fonográfica. Para tanto, além de um exame aprofundado do material musical de algumas de suas composições, a discussão procura associar a construção de sua sonoridade com o contexto da indústria fonográfica e da música popular brasileira daquele momento, trazendo à tona os debates sobre forma e conteúdo numa perspectiva que leva em conta alguns conceitos-chave para a compreensão dessa nova estética: sonoridade, inclusão, recriação e transcriação. • PALAVRAS-CHAVE • Egberto Gismonti; década de
I970; sonoridade; música popular brasileira. - ABSTRACT - This article aims to discuss the beggining of the Egberto Gismonti's trajectory, trying to unveil musical procedures that made part of his carrier's construction during de I970's, giving special attention to his phonografic's production. For that, besides an deeply examn of the musical material from some of his compositions, the discuss seeks to associate the sonority's construction with the cited context, bringing out the debates about form and contents in a perspective that takes into consideration some keys concepts like sonority, inclusion, recreation, and transcription. - KEYWORDS . Egberto Gismonti; I970's; sonority; Brazilian popular music.

Recebido em I6 de fevereiro de 2017

Aprovado em 4 de abril de 2017

MOREIRA, Maria Beatriz Cyrino. Um coração futurista: a construção da sonoridade de Egberto Gismonti no início de sua trajetória (I969-I976). Revista do Instituto de Estudos Brasileiros, Brasil, n. 66, p. I99-220, abr. 2017.

DOI: http://dx.doi.org/Io.II606/issn.23I6-90IX.voi66pI99-220

I Universidade Federal da Integração Latino-americana (Unila, Foz do Iguaçu, PR, Brasil). 


\section{EgBERTO GISMONTI E O CONTEXTO DA MÚSICA POPULAR NA DÉCADA DE I970}

Egberto Gismonti, um dos mais importantes representantes da música instrumental brasileira, mesmo tendo construído uma trajetória pouco afeita aos rótulos, não pôde conter a atribuição do binômio "erudito/popular" a suas composições, dado tanto pelo público como pela crítica musical desde o início de sua carreira. Contudo, na sustentação desse tipo de apreciação, ignora-se uma parte importante e ainda pouco estudada da história e da produção desse artista, que tem origem em um contexto histórico rico e conturbado: a transição das décadas de I960 e I970. É nesse momento específico da história da música popular brasileira, cheio de contradições, confirmações, consolidações e transformações que Gismonti "adentra" esse campo, mesmo que sua imersão no mundo prático musical tenha acontecido anos antes, na infância.

Durante sua juventude, notabilizam-se o protagonismo da família de músicos, da qual faziam parte seu avô e seu tio Edgar (ambos responsáveis pela banda de coreto da pequena Carmo, no estado do Rio de Janeiro, cidade natal de Gismonti), e a formalização dos estudos no Conservatório Nacional do Rio de Janeiro, o qual o artista frequentou até finalizar sua formação em piano erudito.

Os aspectos de sua produção musical inicial, num período localizado entre os anos de I968 - na ocasião da participação de uma de suas mais famosas composições, "O sonho"2, no Festival Internacional da Canção - e meados dos I970, evidenciam conexões com as transformações sociais e culturais que ocorriam no cenário da música popular industrializada brasileira. Entre I969 e I977 o personagem "Gismontiano" parecia ainda não ter assumido a linguagem característica e multidimensional do músico prático que viria a se tornar: o virtuosismo, que mais tarde seria uma das suas habilidades mais reconhecidas através de seus trabalhos-solo ao piano e violão, ainda não se consolidara de forma contundente. Dessa forma, podemos afirmar que nesse período inicial Gismonti aliava-se a uma

2 EGBERTO GISMONTI. Egberto Gismonti. LP. Elenco, I969. 
tendência mais vanguardista, à crença da "experiência do choque e da surpresa" e à experimentação, mesmo que alinhavado às estratégias e às condições de um mercado fonográfico que assistia a uma franca expansão, com suas regras e seus modos particulares de operar.

Desse modo, nesses primeiros anos Gismonti parecia não estar preocupado com a manutenção de uma tradição orgânica que representasse o comprometimento com algum projeto de perpetuação da tradição a partir do material folclórico "original”, ou seja, de cunho nacionalista. Seu projeto parece ser, sobretudo, a busca de um "estilo pessoal”, que foi amparada pela possibilidade de estar compondo, orquestrando e arranjando dentro dessa indústria - seja lá como for - do rock ao baião, do jazz à música de concerto - à maneira de Villa-Lobos, Weber ou Tom Jobim.

A sensação de "pastiche de estilos que constam no bazar"3 ao ouvirmos seus primeiros discos ${ }^{4}$ gravados nesse período esvaece quando mergulhamos em sua obra com o intuito de compreender as estruturas mais profundas de suas construções composicionais e de suas intenções musicais. Egberto desde sempre esteve consciente sobre as escolhas do material, selecionando e reincorporando ideias em suas composições no propósito de explorar ao máximo as transfigurações possíveis dos materiais escolhidos. Essas ideias muitas vezes aparentam nascer de seu "gênio criativo" indomável; e não são poucas as ocasiões em que Gismonti não hesita em realçar a importância da intuição para sua criação artística, afastando-se das premissas racionalizantes do mundo material que o cerca. Contudo, sempre reconheceu que o "aperfeiçoamento" de sua intuição é requisito necessário para poder se expor artisticamente ao mundo, estabelecendo, dentro desta perspectiva, uma conexão com os pressupostos modernistas de apuramento do conhecimento e do gosto.

Com certeza do gosto pra intuição. É claro que sou um intuitivo. Mas só a intuição não é suficiente. Eu tenho que estar certo de que esta intuição tem um gosto, uma apuração. Hoje eu estou certo deste gosto, deste refinamento da minha intuição. Parece egoísta, ou autossuficiente dizer isso. Mas é verdade. Eu tenho que ter certeza disso, ao contrário não ia poder me expor 5 .

É nesse universo de criação e transfiguração que surgem seus primeiros discos,

3 O autor não identificado de um artigo publicado na revista Veja de I969 cita os argumentos da chamada "turma da pesada” (críticos nacionalistas) em relação ao músico: “Não passa de um 'pastiche' dos Beatles, Johnny Alf e Tom Jobim”. EGBERTO, o Io LP. Veja, ed. 36, I4 mai. I969, p. 54. Em nota sobre o lançamento de seu disco Sonho 70, a revista Veja novamente opina: "Mas como violonista é muito Baden Powell, como cantor é mais Edu Lobo e como arranjador, pela forma de usar os metais, é Burt Bacharach. Dele mesmo, conserva a formação erudita e muito enfeitada. O resultado é uma mistura que, acrescida de alguns estilos ainda disponíveis na praça, formaria uma espécie de bazar da música moderna”. SONHO 70. Veja, I97I.

4 Ver informações completas dos discos no final do artigo: Egberto Gismonti (I969), Sonho 70 (I970), Orfeu novo (I97I), Água e vinho (I972), Egberto Gismonti (árvore) (I973), Academia de danças (I974), Corações futuristas (I976) e Carmo (I977).

5 GUIMARÃES, Márcia. Egberto Gismonti - foi difícil me livrar da música erudita. Última Hora, 30/9/1976. 
sobre os quais o músico costura sua "trança” estilística. Esse conceito, discutido por Giovanni Cirino ${ }^{6}$ em seu trabalho sobre música popular instrumental brasileira, fornece uma alternativa às abordagens que utilizam o conceito de hibridismo. De acordo com esse autor,

A MPBI [música popular brasileira instrumental] pode ser pensada metaforicamente como uma corda trançada, formada por diversas linhas, fios que vão emergindo e submergindo à medida que a percorremos. As linhas vão se sobrepondo na tessitura dessa corda, quando uma linha submerge, outras retomam seu papel e dão continuidade à trança?.

De acordo com a justificativa de Cirino, o conceito de "trança” ajuda a compreender o fenômeno da música popular instrumental brasileira dentro da própria lógica interna, e pode ser transposto ao caso do assunto deste artigo. A partir da visualização de uma trança, os elementos de culturas musicais distintas emergem e submergem de acordo com contextos sociais próprios, não dependendo exatamente do "grau de pureza" ou da "precedência histórica” ou até mesmo de hierarquias, mas sim das concepções estéticas e das técnicas disponíveis na escala de produção do objeto, compositores, músicos, produtores e todos aqueles envolvidos na materialização da ideia sonora, ao vivo ou gravada.

É também no período abordado neste artigo que Gismonti prepara o terreno para voos maiores, e aqui nos referimos principalmente ao seu encontro prolífico com o selo europeu ECM Records, reduto do jazz europeu que "buscava se distanciar dos padrões vigentes de jazz e da gravação dos 'Broadway Standards’ através da gravação de novas composições baseadas em paisagens sonoras, sintetizadores, minimalismo composicional, música clássica e música étnica”.

Ao longo deste artigo, observaremos também que a lógica interna das composições de Gismonti rompeu com certas características e sonoridades que vinham sendo estabelecidas no campo da música popular brasileira (MPB), com suas mensagens estéticas específicas e seus nexos contextuais. Na década de I960, após a efervescência dos festivais da canção, parte da indústria cultural e da classe média intelectualizada considerava a MPB - entendida aqui como uma instituição sociocultural pelo conceito de Marcos Napolitano - uma derivação lógica da tradição musical brasileira, um tipo de música que ao mesmo tempo que se modernizava não deixava de lado os elementos que pudessem fazê-la ser reconhecida como portadora

6 CIRINO, Giovanni. Narrativas musicais: performance e experiência na música popular instrumental brasileira. São Paulo: Annablume/Fapesp, 2009.

7 Ibidem, p. 30.

8 TINÉ, Paulo José de Siqueira; PATREZE JUNIOR, Mario A. Procedimentos modais presentes no violão da peça “Cego Aderaldo” de Egberto Gismonti. In: CONGRESSO DA ASSOCIAÇÃO NACIONAL DE PESQUISA E PÓS-GRADUAÇÃO EM MÚSICA - ANPPOM, 25, 20I5, Vitória. Anais... Vitória: Universidade Federal do Espírito Santo-20I5, p. 2.

9 NAPOLITANO, Marcos. "Seguindo a canção" - engajamento político e indústria cultural na MPB (I959-I969). São Paulo: Annablume/Fapesp, 200I, p. I4. 
de uma identidade nacional. Bossa nova e tropicalismo, duas correntes musicais de importância nesse processo, reorganizaram os materiais de referência estética trazendo à tona a descontinuidade entre arte, indústria cultural e vida ${ }^{\mathrm{TO}}$. Mas é na transição das décadas, especificamente no período pós-tropicalista, que se pode observar modificações na forma e conteúdo da produção da MPB. Santuza Naves, em seu livro Canção popular no Brasil: a canção crítica, refere-se a esse processo como o período de "desconstrução da canção", justificado a partir da dilatação do conceito de canção através da incorporação de outros aspectos poéticos, estéticos e musicais à sua estrutura ${ }^{\text {II }}$. A forma fechada da canção, articulada pela relação intrínseca entre letra e melodia, dá espaço para a canção-objeto, a canção-plástica, a canção experimental que ousa se aproximar do território misterioso da música sem palavras. Assim como afirma o pesquisador Sérgio Molina, a canção popular desse período pós-tropicalista "fortaleceu consideravelmente seu corpo musical, seu caminho como "música cantada"'².

Esse corpo musical foi especialmente ampliado e alimentado através da construção de sonoridades, timbres, ruídos, territórios de improvisação, meios eletrônicos, multimídias, montagem, cortes, colagens, fusões e sobreposições. Observa-se assim, ainda de acordo com Molina, que a música popular encontrou-se afetada pelo espírito inventivo e experimental que pairava sobre a música de concerto do meio do século XX e ao mesmo tempo se estabeleceu como "porto seguro para uma sobrevida anacrônica do sistema tonal"

No recorte temático da obra de Gismonti que analisamos neste artigo, é perceptível a utilização de materiais preexistentes de diversas tradições. Neste estudo, optamos por discutir esses procedimentos através dos termos "inclusão" e "recriação", práticas materiais criativas especialmente encontradas na arte modernista brasileira. "Inclusão" e "recriação" podem ser entendidas como atitudes de retomada dos legados culturais de diferentes tradições, manipulados através de ferramentas de linguagens como imitação, pastiche, plágio, paródia, tradução, citação e incorporação. Para ajudar na compreensão dessas práticas, a autora Santuza Naves ativa os conceitos de bricoleur e engenheiro, sendo a atitude do primeiro oposta à do segundo, que rigorosamente constrói seu discurso com matérias-primas e instrumentos que ele mesmo criou. O ponto estratégico de seu pensamento que mais importa aqui é a demonstração de que no pós-tropicalismo a estratégia do bricoleur, includente, flexível e subjetivista, retoma a posição central que mantinha desde o

Io Ibidem.

II NAVES, Santuza Cambraia. Canção popular no Brasil: a canção crítica. Rio de Janeiro: Civilização Brasileira, 2010.

I2 MOLINA, Sergio Augusto. A composição de música popular cantada: a construção de sonoridades e a montagem dos álbuns no pós-década de I960. Tese (Doutorado em Música). Escola de Comunicações e Artes, Universidade de São Paulo, São Paulo, 2014, p. I3

I3 Ibidem, p. 24. 
início do século ${ }^{\mathrm{I} 4}$. Partir dessa referência nos ajuda a pensar e expandir os diferentes sentidos que esses conceitos adquirem com a criação artística do objeto deste artigo.

A hipótese neste trabalho é de que "inclusão" e "recriação" não são categorias que estarão conectadas à ideia de uma cultura nacional unificada e sim a uma retomada de culturas diversas num cenário fragmentado, composto de elementos que não se harmonizam em uma única identidade.

A obra de Gismonti desse período, ainda parcialmente desconhecida, parece propor um tipo de organização desses elementos, e é para a averiguação de sua lógica interna que dirigiremos nossos esforços para desvendar os significados mais profundos de um tipo de música que muitas vezes não faz parte do arcabouço teórico dos musicólogos mais tradicionais. Partindo deste pressuposto, é interessante notar de que modo ela se afasta da concepção modernista tradicional da inclusão como categoria de "manutenção" de determinada identidade nacional, com o intuito de descobrir e desvendar procedimentos estilísticos que parecem se desviar dessa norma.

Outra característica determinante da obra de Gismonti desse recorte histórico que nos orienta para recompormos os sentidos de determinadas "desconstruções" e as proposições criativas do músico é sua tendência comprovada à "transcriação". Compreendemos esse procedimento como um ato de recorrência ao seu próprio material compositivo. Pude constatar a existência de um grande número de regravações, nos discos de Gismonti, de composições de sua autoria.

Luciano Berio escreve uma série de instruções a respeito dessa prática em seu texto-ensaio "Translating music" เ5. O processo de transcrição para Berio é um processo de "tradução" que implica a transferência de um material de um universo a outro, uma experiência musical para uma descrição verbal, um instrumento a outro, ou a transformação do texto musical em performance. Tradução também envolve processos de interpretação. O processo de interpretação da música no ato de uma tradução difere, de acordo com Berio, daquele que ocorre na literatura pelo fato de a primeira se construir com instrumentos e materiais que não são tão permanentes como as páginas escritas. Sendo assim, o recurso da música aos elementos do passado é limitado e vulnerável, pois não lida, a priori, com a problemática da escolha de trair um significado pelo bem de outro (como no trabalho literário, no qual se deve optar por ser mais fiel à tradução literal ou à tradução dos sentidos do poema). De acordo com o autor, as "transcriações" podem trazer à superfície as funções que estavam escondidas por trás de uma dada configuração musical e ampliá-las, sendo compreendidas como "uma interação criativa com a natureza" ${ }^{16}$, um ato contínuo sobre as potencialidades contidas no cerne do material com que se trabalha. Assim, quando dois textos musicais são unidos, eles podem estabelecer o que o autor chama

\footnotetext{
I4 NAVES, Santuza Cambraia. Da bossa nova à tropicalia: contenção e excesso na música popular. Revista brasileira de Ciências Sociais, v.I5, n. 43, junho/2000 p. 44.

I5 BERIO, Luciano. Translating music. In: . Remembering the future. Cambridge. Massachussets/London:

Harvard University Press, 2006, p. 3I-60.

I6 Ibidem, p. 4I.
} 


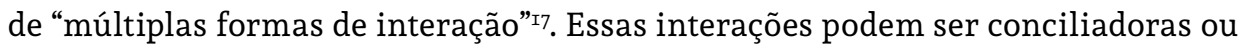
conflituosas. Na opinião do autor, é justamente quando há uma interação conflituosa que pode haver uma conexão profunda com as informações iniciais, as quais serão desafiadas e justificadas. Berio acrescenta que a possibilidade de abusar da integridade do texto inicial é um "ato construtivo" sobre o próprio material. Dessa forma, o ato de transcrever atinge o centro do processo formativo e pode definir a estrutura de um trabalho - "não é o som que está sendo transcrito, mas a ideia"18.

Percebemos que a instabilidade identitária dos primeiros discos de Gismonti é resultado de exercícios criativos com estilos e gêneros já consolidados em um constante diálogo com uma formação musical erudita e com experiências mais ousadas no campo da música comercial. Gismonti, a partir do álbum Árvore e definitivamente após o disco Academia de danças, propõe uma nova noção de música popular brasileira e parece se interessar mais pela forma do que pelo tipo de conteúdo que ela veicula, trazendo à canção popular e suas recriações instrumentais elementos que se afastam dos signos estabelecidos pela "linhagem tradicional" da MPB do pós-I960. Sua relação com a programação das composições, que são quase que totalmente escritas e pensadas antes do momento da gravação, criando um elo com a prática da música de concerto, é confrontada com a abertura proporcionada pela interação com músicos do universo popular, universo esse que geralmente fixa suas origens na tradição oral-aural. Essas novas maneiras de "formar", que a partir dessa premissa podem residir na tão incerta fronteira entre o "erudito e popular", são possíveis graças a um ato crítico que torna conscientes as possibilidades estéticas de então.

Gismonti parece negar a necessidade de referências fixas e agir num contínuo de ações deliberadas de acordo com as escolhas e a eleição de suas próprias regras no decorrer do processo de criação, fazendo da transcrição/reescritura e regravação um dos caminhos criativos essenciais para a realização desse tipo de processo. Essas características se aproximam e substanciam, de certa maneira, a própria essência de algumas práticas experimentais da música de concerto vanguardista.

\section{OS PRIMEIROS SINAIS DA DESCONSTRUÇÃO CONSTRUTIVA DE Gismonti EM “O SONHO” E "JANEla de OURo”}

Os dois primeiros álbuns, intitulados Egberto Gismonti (I969) e Sonho 70 (I970), têm fonogramas de características bem diversas. Entre canções ao estilo de João Gilberto, um estudo para violão e uma homenagem ao guitarrista de jazz Wes Montgomery, aparecem arranjos orquestrais grandiosos. Essas experimentações orquestrais incluem combinações nada usuais no universo da canção popular, como, por exemplo, oboés dobrando melodias junto à voz ou realizando linhas contrapontísticas bastante evidentes. Enquanto o disco Egberto Gismonti teve a produção do músico

I7 Ibidem, p. 44.

I8 Ibidem, p. 45 . 
bossa-novista Durval Ferreira e foi lançado pelo selo Elenco como parte da série de discos “De Luxe” (cujos álbuns dispunham de um orçamento privilegiado), Sonho 70 foi lançado pela Phonogram (antiga CDB, ainda subsidiada na transnacional Philips) e curiosamente contou com a produção de Roberto Menescal ${ }^{\mathrm{I9}}$. No disco, apresenta-se uma seção rítmica que se apoia diversas vezes no tratamento funkeado da "levada" por trás das canções, indicando o flerte contemporâneo daquela geração de músicos com o movimento da música black, representado no Brasil por Wilson Simonal e Erlon Chaves.

A canção "O sonho", por exemplo, aparece em duas versões distintas nos discos citado $^{20}$ e se mostra como um bom exemplo da passagem da linguagem de canção para a linguagem instrumental no decorrer dos anos. No disco de I969 "O sonho" narra uma aventura onírica permeada pela abundante e excessiva orquestração, que transcorre todo o fonograma, dando-lhe ares de música de concerto. Uma única nota executada pelas cordas - um "sib" - simula um horizonte contínuo e permanente, elemento que causou estranheza nos músicos da orquestra do festival, que ficaram desconfiados do texto do estreante. A melodia principal delineada pela escala hexafônica a modulação de trítono proposta entre as seções A e B demonstram a habilidade de um compositor jovem e entusiasta, mas talvez ainda não devidamente "preparado" para o exercício do ofício. Além de essa "monumentalidade" impactante gerar curiosidade aos ouvidos, a canção dispõe ainda de uma seção de introdução vibrante aos moldes das grandes chamadas das músicas que costumavam ser executadas nesses certames.

Já na gravação presente no disco de I970, “O sonho” se coloca em direção oposta à de sua antecessora; a seção de introdução, que surge dessa vez no final do fonograma, condiz com o caráter mais "estridente" e "crescente" da concepção do arranjo. A orquestra evidentemente não é mais o pilar sobre o qual se apoiam harmonia e melodia. Ouve-se a levada funkeada de bateria, percussão e contrabaixo sustentando todo o discurso musical. Por conta do andamento acelerado, a gravação tem sua duração encurtada, enquanto a sonoridade das texturas das seções é acometida por rupturas mais bruscas. Por conseguinte, a quantidade de eventos sonoros desse fonograma se adensa, como por exemplo quando se sobrepõem, a partir de I:27, a melodia principal da seção A e o solo da primeira versão.

Na comparação entre as duas versões, podemos perceber então que, além do reaproveitamento e recriação do material da gravação original de I969 em termos estruturais, é sobretudo à dinâmica sonora dos eventos causados pelo "nível secundário" - o nível da sonoridade - que devemos dirigir nossa atenção. É nela que reside o interesse das transformações que sobejam nos fonogramas setentistas de Gismonti. Esse nível secundário é formado por “texturas, adensamentos, rarefações,

I9 Podemos encontrar semelhante tratamento, por exemplo, no disco Como er porque, de Elis Regina, gravado em I969 pela mesma companhia (ainda com o nome de CDB). Esse disco conta com arranjos de Roberto Menescal e Erlon Chaves.

20 A primeira versão de "O sonho" aparece no disco Egberto Gismonti (I969). A segunda está presente no disco Sonho 70 (I970). Sua terceira e última versão se encontra em Orfeu novo (I97I). 
operações de cortes e filtros de frequência", componentes que agem diretamente sobre o parâmetro da sonoridade ${ }^{2 I}$.

O disco Água e vinho, lançado em 1972 pela Odeon, representa com bastante propriedade as condições do mercado fonográfico daquele momento. Nesse ano, a Odeon era reconhecida por ter como produtores nomes como Milton Miranda e Mariozinho Rocha, profissionais que incentivaram a produção dos discos de músicos do casting mais "nobre" da música popular brasileira, possibilitando seu financiamento, dando-lhes plena liberdade de gravação e horas ilimitadas de uso nos estúdios da gravadora, favorecendo assim a criação coletiva e a experimentação característica da época ${ }^{22}$. O disco, formado em sua grande totalidade por canções compostas em parceria com o poeta e letrista Geraldo Carneiro, além de confirmar a grande habilidade melódica de Gismonti, assinala de modo personalizado o diálogo estético com a roupagem da música de concerto, resultado da presença da sonoridade da Associação Brasileira dos Violoncelos. Essa associação tinha como presidente o violoncelista Peter Dauelsberg e era dirigida pelo maestro Mário Tavares, ambos grandes personagens que, pelas suas enormes contribuições às produções da música popular gravada, mereceriam um estudo dedicado e aprofundado.

A análise da estrutura de "Janela de ouro", canção presente tanto no álbum supracitado como no anterior Sonho $70^{23}$, é outra fonte de informações musicais que nos ajudam a compreender esse processo de desconstrução de sonoridades que aparece na forma, na instrumentação e na forma como os eventos são organizados. A primeira versão da canção de I970 se molda a partir de longas seções que parecem manter a ideia de contrastes sob a distribuição dos elementos temáticos entre os instrumentos num arranjo de caráter "erudito" (termo entendido aqui como seções preconcebidas e distribuições de funções instrumentais predeterminadas). Por sua vez, a segunda versão, presente no disco Água e vinho, se dilui numa sensação de repetição contínua de um groove executado apenas por contrabaixo e piano. Assim, mesmo que as seções sejam percebidas como distintas, há um discurso unificado pela redundância da repetição de determinado padrão, que gera o encadeamento de acontecimentos no arranjo. Enquanto na primeira versão se estabelece a condução

2I Sérgio Molina, em sua tese sobre a canção pós-I960, trata com profundidade o conceito de "nível secundário", baseando-se no trabalho de Didier Guigue. A menção do álbum Sgt. Peppers, dos Beatles, talvez seja a melhor forma de exemplificar, no plano da música popular industrializada, os avanços da tecnologia de gravação que interferem na resultante sonora do todo, ou seja, do nível secundário: "Em outras palavras a diferença, por exemplo, entre o Sgt. Peppers e álbuns de outros artistas - e até mesmo entre o Sgt. Peppers e os primeiros álbuns dos Beatles - se fazia muito mais perceptível na sonoridade resultante do fonograma, nos grandes contrastes de texturas, densidades, dinâmicas, no peso e na confluência de diferentes frequências e harmônicos ao longo de cada faixa (e também ao longo de cada 'lado' do disco), do que no fato de que as novas canções exploravam novas formas de construção melódica, outros objetos temáticos nas letras, ou uma ampliação da exploração da harmonia no contexto tonal ou modal". MOLINA, Sérgio Augusto, op. cit, p. 78.

22 MOREIRA, Maria Beatriz Cyrino. Fusões de gêneros e estilos na produção da banda Som Imaginário. Dissertação (Mestrado em Música). Instituto de Artes, Universidade Estadual de Campinas, Campinas, $20 I I$.

23 A primeira versão de "Janela de ouro" está presente no disco Sonho 70 (I970). Sua segunda versão encontra-se no álbum Água e vinho (I972). 
rítmica de contrabaixo e bateria sobre o groove característico sustentado pelo acorde de dó com sétima menor ( $\left.\mathrm{C}^{7}\right)$ no qual são executadas as frases melódicas distribuídas em combinações instrumentais de piano + flautas ou piano + contrabaixo, na segunda versão o pensamento harmônico mantém-se nessa mesma região, excluindo, no entanto, boa parte das referências à escala blues, priorizando a intenção "mixolídia" de caráter mais regionalista e aproximando a composição de um universo mais relacionado à linguagem musical "abrasileirada".

As cordas da segunda versão assumem uma função distinta daquela que desempenharam na primeira, executando tremolos, repetição sincopada de notas (articulação não muito usual para instrumentos de cordas) e exploração de harmônicos, abrindo outras possibilidades sonoras experimentais. Elementos utilizados no arranjo da primeira versão se apresentam de forma livre na improvisação, demonstrando que Gismonti vai construindo um vocabulário musical próprio a partir de um contato vivo e provocante com o do material preexistente. Outro fator de suma importância é que na segunda versão de "Janela de ouro" Egberto parece também sedimentar procedimentos pianísticos que farão num futuro parte de sua linguagem como solista no piano (caso dos solos de piano sobre melodias abertas em sextas paralelas).

Em I973, Gismonti lança o disco conhecido pelo título de Árvore, no qual se mesclam faixas instrumentais e canções. Os arranjos aparentam estar mais organizados, sobretudo do ponto de vista da escrita orquestral. "Tango" é um exemplo contundente da forma como Egberto desenvolvia seu estilo pianístico peculiar. A faixa intitulada "Academia de danças", dividida em duas seções, "A dança dos homens" e "A dança das sombras", apresenta experiências sonoras serialistas, bem como exploração timbrística diferenciada dos instrumentos.

Ao conhecer o repertório rico e diversificado dos discos desse período, percebemos que podemos trazer à superfície inúmeros exemplos - de modo que nos distanciemos das profundezas misteriosas da "fronteira" erudito/popular - que ajudam a corroborar a existência de um processo de "desconstrução construtiva" no contínuo das propostas composicionais de Egberto ao longo da década de I970. Desconstrução em diversos níveis, que contribui na esfera da produção de canção do pós-I960, corroborando e expandindo a tese já postulada de "desconstrução da canção" e fundamentando a aproximação gradativa de Gismonti com a linguagem da música instrumental e com o experimentalismo, além de documentar com mais propriedade seu amadurecimento como instrumentista.

É em I974, ao incorporar outras referências de gêneros e estilos e se valer mais da forma como toca do que do próprio conteúdo, que Gismonti constrói uma linguagem cada vez mais universal, episódica no que tange à descrição formal, desconstrutiva no plano da fragmentação dos momentos e que, além de tudo, desloca os elementos "nacionais" ou "regionais" para outros planos de significados.

Embora o intuito de nosso estudo seja ampliar sobretudo a compreensão estética que se tem da obra desse artista, tomamos como orientação o fato de que esse entendimento pode contribuir na revelação de transformações na noção de "identidade nacional". Partindo da perspectiva desenvolvida por Michel Nicolau, situamos Gismonti num momento histórico no qual as grandes narrativas - 
principalmente aquela ligada às concepções de uma identidade nacional-popular homogênea, combatentes dos fenômenos do mundo moderno, como o mercado, o estrangeirismo, a perda da identidade nacional pura etc. - estão atuando de forma diferente, rodeadas de "outras narrativas que se propõem particularistas" 24 . Nesse contexto, o artista se vê inserido em outro cenário de pluralidade de ideias, de circulação de informações pelas mídias, e deve se posicionar em meio "a uma enigmática diversidade de opções e possibilidades”25.

Nossa intenção é reforçar a ideia de que Gismonti revela traços dessas transformações na identidade, identidade essa que mesmo estando atrelada às sugestões de um passado modernista se desenvolve na perspectiva de um processo de "desconstrução-construtiva", que em certa medida tem conexões com um cenário "pós-moderno" que acusa a nova condição "globalizada" do artista. Dessa maneira, a "identidade nacional" do pós-I970 incorpora cada vez mais o signo da diversidade cultural, que ganha valor e amplidão validando a convivência entre autenticidade e hibridismo. O híbrido passa a ser a numeração dos elementos diversos e não mais a síntese deles. Assim, podemos dizer que efemeridade, flutuação, impermanência e pluralismo cultural - elementos que se destacam nesse processo de transformações ${ }^{26}$ - são materializados em diversos níveis nas composições de Gismonti a partir da década de I970.

\section{O disco Academia de danças (1974)}

Em I974, com o lançamento do LP Academia de danças, dá-se o início de uma nova fase na carreira de Egberto. A produção desse disco é resultado da perspicácia profissional de Gismonti em perceber a crise que a gravadora Odeon atravessava naquele momento, confirmada, por exemplo, pela suspensão dos contratos com diversos de seus artistas já renomados. Egberto, antecipando a possibilidade de ter seu contrato rescindido com a gravadora, resolve propor um projeto grandioso e experimental, que tinha como objetivo misturar ao máximo todas as informações musicais absorvidas até então:

[...] a Odeon começou a entrar numa certa crise, [...] a renovação do meu contrato não tinha sido feita [...] eles tinham feito um aditivo que era mais um disco. E eu senti, pelas minhas contas, setenta e tal. Eu digo: "bom, se tem gente pra caramba aqui conhecida,

24 NETTO, Michel Nicolau. Discursos identitários na música popular brasileira. Dissertação (Mestrado). Departamento de Sociologia, Instituto de Filosofia e Ciências Humanas, Universidade Estadual de Campinas, 2007, p. II7. Disponível em: 〈http://www.bibliotecadigital.unicamp.br/document/?code=vtlso00424I82\&fd=y >. Acesso em: 6 abr. 2017.

25 Ibidem, p. II9.

26 HALL, Stuart. A identidade cultural na pós-modernidade. Io. ed. Rio de Janeiro: DP\&A, 2005, p. 74. 
como Edu Lobo, Francis Hime, e eles estão mandando embora, eu que não sou nada ainda, vou ser mandado embora é já, não é?”27.

Dentro da história de Egberto, Academia de danças representa um de seus trabalhos mais contundentes em relação à diversidade de gêneros e tipos de experimentos musicais. Melodias líricas ao estilo das canções de Água e vinho e experimentações orquestrais semelhantes às do disco Árvore foram conjuradas num emaranhado de citações e elementos mais "populares" e "abrasileirados" retirados não só do universo regionalista como também das raízes mais profundas brasileiras; a música indígena. Tudo isso era capturado e absorvido por um sistema tecnológico de gravação ainda incipiente, mas que possibilitava um tipo de experimentação em estúdio que não seria possível em qualquer período histórico posterior.

Outra característica muito evidente na sonoridade do disco era o flerte com o jazz-rock ou fusion, termo pelo qual esse gênero é mais reconhecido. Dito gênero teve sua origem em finais dos anos I960 na proposição da união da sonoridade visceral do rock com a complexidade improvisatória do jazz. Um dos álbuns considerados pioneiros desse tipo de crossing over é o disco Bitches brew, do trompetista Miles Davis. Gravado em I969, esse álbum apresenta composições que se distanciam da forma swingada de tocar do jazz tradicional, explorando a sonoridade dos instrumentos elétricos e os grooves de contrabaixo, percussões, efeitos e pedais eletrônicos. Muitos dos músicos que participaram das gravações de Bitches brew incorporaram essas concepções sonoras nas próprias carreiras. Entre eles podemos citar o pianista Chick Corea (com o grupo Return to forever), o guitarrista John McLaughlin (com sua The Mahavishnu Orchestra), o percussionista Airto Moreira e o saxofonista Wayne Shorter (com o grupo Weather Report). Gismonti conta em entrevista que John McLaughlin identificou semelhanças de sua música com o gênero:

Quando chegamos aqui e entraram os sintetizadores e eu ainda botei uma orquestra em cima que deu a dimensão mais apocalíptica, como dizia o MacLaughlin: "mas isso é rock puro, mas ao mesmo tempo não é rock”. Eu dizia: "olha, rock não é não porque eu não sei rock, como não?” “Você sabe jazz?” eu digo: “Jazz também, não [...]”28.

O projeto vislumbrado por Gismonti obteve resultados bastante significativos. $\mathrm{O}$ disco acabou sendo o mais vendido de todos seus lançamentos até então. Em I976, o jornal Folha de S. Paulo publicava:

Academia de danças tem lugar importante no coração de Egberto Gismonti. Foi o disco que lhe permitiu parar de esquentar a cuca. É o que convenceu sua gravadora de que

27 GISMONTI, E. Egberto Gismonti. Academia de danças. EMI Odeon, I974. Memória da música brasileira. Som do vinil. 20I5. Entrevista concedida a Charles Gavin. Disponível em: <http://osomdovinil.org/egberto-gismontiacademia-de-dancas-emi-odeon-I976/>. Acesso em: 5 abr. 2016.

28 Ibidem. 
ele poderia ser vendável, dentro dos seus limites: o LP vendeu I5 mil exemplares, o que para Egberto, é muito ${ }^{29}$.

Curiosamente, ao mesmo tempo que se registrou o aumento de vendas, a crítica especializada passou a caracterizá-lo como um álbum de "difícil fruição". Egberto, em I975, expõe esse impasse, comparando a postura da indústria fonográfica brasileira e a americana diante seus trabalhos:

Quando saí daqui, falaram que o meu disco [Academia de danças] era muito enrolado. Saí triste. Mas quando eu cheguei lá, os diretores das gravadoras dos EUA acharam ótimo!!! A Academia de danças tem um som técnico que eu acho anormal do Brasil. Mas eu não posso culpar quem não entende. Pois se eu mesmo só comecei a entender a direção da minha música sete anos depois. A gravadora dá a entender a gente que no Brasil só existem pessoas muito burras e que no seu espetáculo não vai ninguém ${ }^{30}$.

A constante referência à expressão "música de qualidade" tornava cada vez mais distante qualquer possibilidade de categorização da música feita por Gismonti naquele período. Dizia o jornal Última Hora: "Ninguém, absolutamente ninguém conseguiu definir, rotular ou explicar sua música de sons estranhos e belos, nascidos, sobretudo, da sua emoção"3i. Mais uma vez observamos indícios que nos levam a crer que as produções culturais criadas pelo músico não eram mais constitutivamente oposicionistas em sua essência, não se tratando de um hibridismo resultado da justaposição de elementos contrastantes. Dessa forma, esse tipo de produção se afasta da orientação dos debates que se construíam no campo da música popular brasileira na década anterior em torno das polaridades nacional-internacional, arcaico-moderno, alienado-engajado. O jornal Última Hora destaca essa característica multipolar da obra de Gismonti, apontando para um cenário cultural segmentado a partir do momento em que cita a existência de "qualquer tipo de sensibilidade":

O mais surpreendente na música de Egberto é que os sons criados por ele atingem qualquer tipo de sensibilidade. De repente, Miles Davis procura Egberto para produzir um disco, do mesmo jeito que a Som livre estabelece contatos com os músicos para um LP infantil, e Jean Pierre combina a trilha sonora de um filme sobre a demarcação de terras no Alto Xingu e Turíbio Santos grava em Paris suas composições. O que é isso? Uma música que serve pra absolutamente tudo32.

Academia de danças é dividido em duas "seções". De um lado, os fonogramas de música instrumental se apresentam sem interrupções, com os finais emendados uns aos outros. De outro, duas canções acompanhadas apenas por piano; uma regravação

29 CAMBARÁ, Isa. Egberto - "Estou é pra lá de Bagdá". Folha de S. Paulo, Ilustrada, 25/12/1976.

30 PENTEADO, Regina. Gismonti, ponto de encontro de vários extremos. Folha de S. Paulo, Ilustrada, 6/9/1975.

3I GUIMARÃES, Márcia, op. cit.

32 Ibidem. 
de "Vila Rica" em versão instrumental (cuja gravação original se faz presente no disco Água e vinho), uma composição intitulada "Continuidade dos parques" e duas faixas que trabalham com sonoridades e temas musicais indígenas. Diferente da estética "monumental" presente nas composições dos discos anteriores, a partir de Academia de danças Gismonti parece não estabelecer mais uma ligação com os cânones de uma arte "erudita". Isso quer dizer, dentre outras modificações, que os arranjos não acrescentam um naipe de cordas para aumentar a massa sonora da execução, para costurar frases contrapontísticas que possam servir de enriquecimento sonoro das melodias ou de sustento harmônico para as mesmas. No disco, o naipe de cordas é arranjado de forma a criar "ambientações" e "sonoridades" distintas para cada faixa. No fonograma intitulado "A porta encantada", por exemplo, no primeiro lado do disco, as cordas aparecem em momentos específicos do arranjo apoiando convenções rítmicas, como, por exemplo, na realização de um pizzicato em polirritmia com um ostinato tocado ininterruptamente por violão e sintetizador.

\section{UM CORAÇÃO FUTURISTA SE CONSTRÓI COM SONS - A CONSOLIDAÇÃO DE UMA NOVA SONORIDADE}

No álbum Corações futuristas, de I976, considerado uma extensão de seu predecessor, e nas turnês que o sucederam, Gismonti passa a expressar um novo modo de fazer música. Através da criação coletiva e da improvisação, concebe uma nova maneira de pensar a organização dos sons explorando cada vez mais os inovadores recursos tecnológicos e se atendo mais à forma ou ao "como fazer" do que a um conteúdo específico que possa ser associado a algum tipo de discurso ou escolha estética normatizadora. No trecho de uma de suas entrevistas transcrito abaixo, Gismonti questiona o papel do artista naquele contexto reavaliando sua obra anterior:

Para citar um exemplo: para que ficar pondo cordas numa música que não pede cordas, apenas para soar sinfônico, falsamente sinfônico, pois sinfônico mesmo é outra coisa, outros músicos, outra estrutura de música? Por que fazer isto só porque eu tinha decidido que essa era a minha forma de música? Por que não tocar simplesmente, do jeito como eu tinha composto? [...] Por que ficar horas e horas intelectualizando, discutindo nossa posição na sociedade brasileira, nosso papel, e tal, tudo com copo de uísque na mão e o ar-condicionado ligado? Quer dizer, falso, irreal33.

Voltado ao "como" e não ao "o que" tocar, Gismonti se reuniu a um selecionado grupo de músicos, os quais - de acordo com o próprio - eram "pessoas acrescentando, me permitindo parar para ouvir minha própria música"34. No Jornal do Brasil, o crítico musical Tárik de Souza parece reforçar essas escolhas quando diz: "Para Egberto, o novo trabalho dirige-se especialmente para o 'como' e não 'o quê'. É muito

33 BAHIANA, Ana Maria. Nada será como antes: MPB anos 70 - 30 anos depois. Rio de Janeiro: Editora Senac

Rio, 2006, p. I57.

34 UM MÚSICO, enfim, entendido. Folha de S. Paulo, Ilustrada, 5 jun. I976, p. 26. 
o tocar, uma maneira de tocar" ${ }^{35}$. Gismonti responde descrevendo a dinâmica de seus shows, mencionando os momentos de improvisação e a consequente criação de uma atmosfera sonora específica com a intervenção e utilização dos aparelhos tecnológicos:

O show tem uma parte só, não tem intervalo, porque quebra a atmosfera. Em São Paulo nós fomos tocando, quando sentimos tinham passado duas horas. [...] Nós tocamos mais meia hora. Eu entro e faço uma meia hora sozinho, na abertura. [...] Fica difícil detalhar o que acontece, porque é um violão preparado para ter o mesmo volume de guitarra, com microfone embutido, o som passa por space echoes, phasis, pedais. Então é um volume sonoro que vai girando, de repente aparece um buraco uma ideia puxando para outro caminho, e nós vamos por ali36.

É importante destacar que a temporada que Gismonti havia passado nos Estados Unidos durante I975 gravando com o percussionista brasileiro Airto Moreira levou o músico a tomar conhecimento dos instrumentos elétricos disponíveis no mercado, verdadeiras novidades no meio musical daquela década. Dentre eles estão, por exemplo: o Arp Odyssey, um sintetizador analógico lançado em I972 pela Moog Music, um dos primeiros sintetizadores com capacidade duofônica (habilidade para tocar duas notas ao mesmo tempo) ${ }^{37}$; o Arp String Ensemble, um sintetizador, produzido pela Eminent NV (Solina) e lançado em I974, que era capaz de reproduzir o som de seis instrumentos (violino, viola, trompete, trompa, violoncelo e contrabaixo) junto a um efeito chorus, que lhe dava o som polifônico característico; o Space Echo, um aparelho de efeito também conhecido como Roland RE-2OI e lançado em I974 que produzia delay analogicamente através da manipulação de fita magnética; e o Mutron biphase, um pedal criado por Mike Beigei e Aaron Newman na empresa norte-americana Musitronics entre os anos de I973 e I974, que, assim como denota seu nome, proporcionava ao instrumento o efeito de dois tipos diferentes de phaser que podiam funcionar individualmente ou em série (mono ou estéreo) e permitiam o controle dos parâmetros (tipos de onda, profundidade e feedback) ${ }^{38}$.

A prática "improvisada” dessa nova fase, distante das premissas estruturantes de suas origens no jazz, junto à configuração das apresentações ao vivo, que fizeram surgir uma nova concepção de criação, eclodiu simultaneamente ao rompimento com um ideal de artista que constrói sua individualidade aos moldes modernistas.

35 SOUZA, Tárik de. Do parto erudito à criação coletiva. Jornal do Brasil, Caderno B, p. 5, 9 jun. I976.

36 Ibidem.

37 Esse instrumento foi também o primeiro sintetizador tocado por Herbie Hancock em seu disco de I973, Head hunters.

38 Sobre Academia de danças, Corações futuristas e a curta temporada nos Estados Unidos, Gismonti comenta:

"Eu vou botar tudo que me ensinaram junto. E por isso tem eletrônica. A eletrônica é por conta do Herbie Hancock. Que eu morei em Nova Iorque em I975, I976 pra fazer o disco do Airto Moreira, Identity. E o Herbie Hancock topou participar do disco e a gente tocou muito junto. E eu ia pra garagem dele, que tinha um estúdio e trouxe essas coisas pra mim, pra casa e estava tocando”. EGBERTO GISMONTI, E. Egberto Gismonti. Academia de danças. EMI Odeon, I974, op. cit. 
Contribuem para esse processo a relação com a tecnologia, as referências da experiência de um mundo fragmentado e o desprendimento das noções antagônicas como uma herança do modernismo. Todas essas características abrem espaço para a desarticulação de identidades do passado e a possibilidade de novas associações de elementos advindos de diversas culturas, práticas presentes em diversos trabalhos de música instrumental brasileira a partir da década de I970. Um novo ideal de artista é proposto, um artista atuante que prioriza a performance em suas diversas dimensões, o estilo como elemento formador, muito mais do que estruturante de um conteúdo musical específico.

No relato que Gismonti faz sobre um dos shows do álbum Corações futuristas podemos perceber todo esse arsenal criativo discutido no parágrafo anterior:

Houve um momento no show de São Paulo que estava um free pesado (quando falo free é uma coisa brasileira calcada numa harmonia ou num ritmo, nada a ver com Nova Iorque), uma zoeira que você nem imagina. De repente, o Robertinho saiu da bateria e começou a fazer um som na tabla. Ninguém ouvindo. $\mathrm{O}$ som foi morrendo, o Nivaldo largou o sax-soprano, pegou uma flauta, o Luis largou o baixo, pegou um caxixi e eu umas flautas estranhas, que eu trouxe da Tailândia. Ficou aquele clima diferente fui para o piano e cantei "Bodas de prata" 39.

Os jornais de uma maneira geral pareciam estar atentos às modificações da sensibilidade daquele momento. Arrematando o debate proposto neste item final trazemos outra descrição pertinente, uma matéria não assinada do jornal Folha de $S$. Paulo:

Aliando o indígena e o popular, o ocidental e o oriental, a erudição tradicional e as técnicas recentíssimas de composição, estruturação e execução, ele e seu grupo (Luis Alves no baixo, Robertinho na bateria, Nelson Ângelo na guitarra e Nivaldo Ornellas no sax) parecem perseguir a abertura em relação a todos os conceitos melódicos e uma criação propositadamente desarrumada (no sentido do não preestabelecido), bem a gosto do seu líder ${ }^{40}$.

\section{A NaRrativa EPISÓdica dE "DANÇa das CabeÇas"}

Dentre as faixas que podem melhor ilustrar essa desconstrução formal e a aproximação com o universo do fusion, trazemos aqui o exemplo de "Dança das

\footnotetext{
39 SOUZA, Tárik de, op. cit.

40 UM MÚSICO, enfim, entendido. Folha de S. Paulo, Ilustrada, 5 jun. I976, p. 26.
} 
cabeças" ${ }^{\prime \prime 1}$, uma de suas composições mais conhecidas e tocadas, a qual procuraremos analisar com mais detalhes.

O fonograma se estende por oito minutos e meio de seções contrastantes estruturadas por dois "temas" principais. Logo na introdução, a incerteza rítmica e harmônica marca o ambiente sonoro juntamente com o efeito do pedal mutronbiphase sobre um loop de dois acordes: lá menor (Am) e fá maior com a terça no baixo (F/A). Ao executar as notas lá, mi e sol, o contrabaixo afirma o que optamos por chamar-em termos harmônicos - de "centricidade" na região de lá, enquanto a bateria explora os timbres de suas peças aleatoriamente. As posições constantemente alteradas dentro do espectro estereofônico da gravação alteram a "espacialização relativa"ł2 da instrumentação em questão.

Ao longo da escuta de "Dança das cabeças" é possível ter certeza de que o resultado sonoro das composições é determinado pelas manipulações sonoras de estúdio; é através dela que um ou mais instrumentos ganham destaque, se justapõem e se alternam, tanto de forma gradativa como repentinamente. Não há, no que chamamos tema A e tema B, um modelo melódico que poderia ser associado a alguma estrutura de período, sentença ou seus híbridos, nos termos convencionais das estruturas de fraseado. A coesão harmônica também não nos dá material suficiente para compreendermos uma progressão com começo meio e fim do ponto de vista da harmonia tradicional.

O Tema A é construído a partir de um padrão idiomático no modo mixolídio realizado pelo violão, que pela sua sonoridade invoca uma espécie de galope nordestino, que na repetição irá ganhar a participação das flautas transversais, simulando a sonoridade das bandas de pífano da Região Nordeste do Brasil. Esse ambiente regionalista é contrastado por uma espécie de convenção que rompe com a sonoridade do modo mixolídio, resultando num ritmo funkeado sobre tríades perfeitas maiores, sol maior (G), sol sustenido maior (G\#) e lá maior (A). No Tema B (de I:04 a I:I6 do fonograma), o contrabaixo retorna as notas lá e mi, persistindo na centricidade harmônica da região de lá. Violão e sintetizador executam frases melódicas de caráter virtuosístico construídas sobre a escala de lá mixolídio e pentatônica menor de lá, resultando numa textura homofônica para essa seção.

Até o retorno de Tema A no fim do fonograma, temos dois momentos distintos na composição. Um deles, que se inicia aos 2:II e chega até os 5:Io, e um segundo momento, que parte dessa minutagem até 6:30. No primeiro, uma "ponte" formada por uma textura homofônica, na qual uma série de acordes parece ter como base a

4I Essa faixa está presente no disco Corações futuristas (I976). É importante lembrar que a composição também dará nome ao álbum que Gismonti gravou com Naná Vasconcelos em I977. No mesmo ano, também foi registrada no álbum gravado com o músico norte-americano Paul Horn, chamado Altitude of the sun, no qual estão também presentes regravações de “Bodas de prata”, "Altura do sol”, “Carmo” e "Parque Lage”. No arranjo da versão desse LP, Gismonti conserva uma estrutura muito semelhante à gravação que aqui analisaremos, com a diferença de que as seções "Tema C", "Interlúdio" e "Interlúdio II” não ficam evidentes e claramente segmentadas como nesta versão.

42 "Espacialização relativa: posicionamento de cada instrumento, voz ou unidade sonora no espectro estereofônico, mais à direita (R), centralizada (C), ou à esquerda (L)”. MOLINA, Sergio Augusto, op. cit., p. 99. 
escala simétrica formada pelas notas tocadas pelo contrabaixo, anuncia as seções de improviso de sax e sintetizador. Essas seções de improviso são intercaladas por momentos de "convenções", nas quais, vale dizer, o contrabaixo figura à frente dentro da reverberação do espaço acústico, enquanto violão e sintetizador permanecem realizando apenas uma nota repetidamente. Desenvolve-se a partir do estabelecimento dessa pulsação marcada pelas notas do violão uma convenção que se assemelha bastante às características estilísticas do fusion dos anos I970. Construídas numa textura homofônica, essas seções possuem uma alteração da métrica (compasso simples para composto) e fazem uso da sonoridade da pentatônica menor de lá e dos acordes formados por intervalos de quintas paralelas.

A transição entre ponte e seção de improviso, aos 2:23, expõe um contraste de sonoridades mais contundente, muito distante daquilo que se esperaria de uma seção de improviso "tradicional", onde um instrumentista improvisaria sobre progressões preexistentes de tamanhos definidos, o trecho propõe a mudança da pulsação dentro de um tempo mais estendido (o improviso dura aproximadamente 44 compassos). $\mathrm{O}$ violão realiza uma espécie de acompanhamento sobre arpejos, a harmonia "vagante" não pressupõe uma chegada a um repouso, enquanto as quintas paralelas apoiadas pelo arp string parecem caminhar sobre a sonoridade do modo lá frígio, justificado tanto pela nota pedal do contrabaixo (lá) quanto pelas diversas aparições do si bemol. Os efeitos do mutron biphase estão presentes durante o improviso e acompanham o aumento da densidade rítmica proposta pelo improvisador, que ao final expande a sonoridade de seu solo através da exploração de outros efeitos do instrumento.

A seção de improviso do sintetizador decorre da sonoridade sugerida na convenção anterior. De duração menor, essa improvisação apresenta outra proposta harmônica, tendo novamente como centro a nota lá, circundada de diversas maneiras pelo contrabaixo. Sobre essa espécie de sonoridade "pedal" centralizando-se em lá, ouvimos num pequeno trecho da seção a utilização dos acordes perfeitos maiores fá (F) e sol (G). Essa sequência de acordes, que podem ser entendidos como os graus bVI (F) e bVII (G) sobre o pedal de lá, fornece ao excerto uma progressão relacionada ao modo eólio. No restante da seção, ouvimos um padrão com a seguinte sequência de acordes: A (lá maior) - A - Bb (si bemol maior) - A, novamente modal, enfatizando a sugestão sonora frígia através da alteração "b2" sobre lá.

A partir da descrição acima, podemos observar que as duas seções de improviso diferem bastante em estilo e caráter. Enquanto o saxofone se comporta de maneira mais estendida, num estilo de improviso que nos remete ao free jazz, com frases longas e exploração dos efeitos do timbre de seu instrumento, Gismonti realiza um improviso caracterizado por motivos curtos e densos explorando principalmente as notas e a sonoridade da escala blues de lá e de sua pentatônica maior.

Aos 5:Io do fonograma um terceiro tema parece se manifestar, marcando o ápice do arranjo através da intensificação de padrões melódicos rápidos e de sobreposições de pulsações diferentes numa seção claramente convencionada. Trata-se também de um trecho musical extremamente curto e de grande atividade rítmica e melódica.

A partir de 5:35 um longo episódio dividido em três momentos diferentes prepara o retorno ao tema principal. No primeiro momento (até 6:00) percebemos o contraste 
da textura causado pelo cessar dos elementos musicais anteriores. A condução da bateria executando um ritmo de baião fornece o sustento das inserções melódicas dos outros instrumentos. Adicionam-se primeiramente as flautas, restabelecendo a alusão à sonoridade dos pífanos, na execução de uma melodia ascendente apoiada na escala de lá mixolídio com a quarta nota aumentada. Em seguida, como numa resposta, violão executa um padrão de quatro notas sobre a estrutura de uma escala de tons inteiros partindo das notas de um acorde diminuto. É importante frisar que novamente temos a recorrência ao pedal em lá, marcado pontualmente pelo contrabaixo.

No segundo momento ouvimos um "corte" entre uma seção e outra, que ressurge com o pontilhado do violão, que alude ao timbre da viola caipira ampliada pelo efeito de um reverb. A marcação pelo contrabaixo da nota "lá" persiste enquanto o violão realiza uma melodia que invoca novamente a sonoridade do modo mixolídio com a quarta aumentada. No terceiro momento, sob a figura rítmica do baião executada pelo contrabaixo, os demais instrumentos interagem numa improvisação livre que amplia o espectro sonoro desse trecho.

Após retorno aos temas A e B, segue-se uma “coda”, que mistura as sonoridades de modo eólio e mixolídio se desenvolvendo para fechar toda essa narrativa episódica de "Dança das cabeças".

Podemos concluir, então, que nessa versão de "Dança das cabeças” há uma transposição dos elementos musicais que invocam uma sonoridade regionalista para um ambiente futurista e experimental, descolando-os de suas raízes e origem. A forma episódica do fonograma, com suas complexidades rítmicas e suas “convenções”, fornece dados para a aproximação desse tipo de sonoridade com o fusion. A centricidade harmônica em torno da tonalidade de "lá", sob suas múltiplas derivações (lá mixolídio, pentatônicas de lá maior, pentatônicas de lá menor, lá eólio, lá frígio), distancia-se totalmente de um nexo harmônico tradicional, aproximando-se do modalismo e justificando-se no processo de "centricidade". As diferenças e/ou permanência de sonoridades no decorrer das seções demonstram que os recursos tecnológicos e de manipulação dos sons influenciam diretamente no resultado da forma. Importante destacar que a mixagem e o estabelecimento da proporção de espaço e volume que cada instrumento ocupa e adquire no espectro sonoro do fonograma também exercem total influência na elaboração da permanência ou ruptura dos parâmetros de sonoridade.

A linguagem performática de "Dança das cabeças", fruto das condições dos equipamentos e procedimentos de gravação da época, é um exemplo bastante expressivo do tipo de composição e fazer musical coletivo que continuará a aparecer nos discos seguintes de Gismonti. Nessa nova poética musical o jogo entre "abertura" e "fechamento" se desenvolve dentro de uma narrativa complexa que não opera mais com o binômio "tensão" e "resolução". O desenvolvimento das seções não se conforma na horizontalidade de "O sonho" ou de "Janela de ouro", mas também não chega a propor sugestões musicais totalmente fragmentadas e imagéticas, como acontece na estrutura formal da instigante canção "Trem noturno", presente no álbum Corações futuristas, cuja audição também se faz indispensável para a compreensão da potencialidade criativa da música de Gismonti desse período. 


\section{CONSIDERAÇõES FINAIS}

Neste artigo procuramos levantar alguns aspectos importantes sobre o início da carreira de Egberto Gismonti, buscando dados contextuais que pudessem ajudar na compreensão do estilo desse importante personagem da música instrumental brasileira, representante do estereótipo de músicos "fronteiriços" que atravessam os territórios da música erudita e popular. Na apreciação estética das composições de seus primeiros álbuns é possível observar um estilo em construção que subsiste do flerte com a forma canção mas que gradativamente passa a explorar o novos caminhos da experimentação, estimulados pelas transformações da sensibilidade do artista pós-I970, que reflete em suas criações a circulação de informações, o desenvolvimento da tecnologia e a articulação entre diferentes culturas.

Na construção da argumentação em torno do objeto discutido, é irrefutável a ideia de que as noções antagônicas já não são suficientes para explicar as formulações criativas de um músico como Gismonti. Nossos ouvidos, ao defrontar-se com esse tipo de criação musical, voltam-se às rupturas, às quebras, às fragmentações, às superposições, trazendo o parâmetro da sonoridade - demonstrado aqui como conceito estabelecido - como um novo indicador perceptivo através do qual capturamos a obra como um todo.

Interessante apontar novamente que a obra de Egberto Gismonti do período analisado pode revelar uma noção de que seria possível ser "moderno" sem levar em conta uma ideia homogênea do é que é ser "nacional".

Essa noção corresponde, como comprovamos no exame detalhado dos exemplos musicais deste artigo, à incorporação e inclusão de elementos musicais de gêneros e estilos diferentes organizados a partir dos parâmetros dados pela manipulação dos timbres e dos sons na gravação, pela interação entre os músicos e pelo tipo de sonoridade desejada; todos esses elementos fornecem novos sentidos aos procedimentos de inclusão, recriação, transcriação e experimentação. Esse conjunto de ações contextualizadas se conjura no processo que chamamos de "desconstrução construtiva”; o ato de criar sobre materiais preexistentes, Egberto o faz com um sentido próprio bastante peculiar, que pode iluminar os caminhos das descobertas sobre o universo misterioso da fronteira, que aflui nesse rico e imenso campo que chamamos de "música popular instrumental brasileira". 
MARIA BEATRIZ CYRINO MOREIRA é doutora em Música pela Universidade Estadual de Campinas e professora do curso de Música da Universidade Federal da Integração Latino-americana (Unila).

E-mail: biacyrinom@gmail.com

Discografia

EGBERTO GISMONTI. Egberto Gismonti. LP. Elenco, I969.

Sonho70. LP. Polydor, I970.

. Orfeu novo. LP. Corona Music Jazz, I97I.

. Água e vinho. LP. Odeon, I972.

. Egberto Gismonti - Árvore. LP. Odeon, I973.

. Academia de danças. LP. EMI-Odeon, I974.

. Corações futuristas. LP. EMI-Odeon, I976.

. Carmo LP. EMI-Odeon, I977.

\section{REFERÊNCIAS BIBLIOGRÁFICAS}

BAHIANA, Ana Maria. Nada será como antes: MPB anos 70 - 30 anos depois. Rio de Janeiro: Senac, 2006. BERIO, Luciano. Translating music. In: Remembering the future. Cambridge. Massachussets/London: Harvard University Press, 2006.

CAMBARÁ, Isa. Egberto - “Estou é pra lá de Bagdá”. Folha de S. Paulo, Ilustrada, 25/I2/I976.

CIRINO, Giovanni. Narrativas musicais: performance e experiência na música popular instrumental brasileira. São Paulo: Annablume/Fapesp, 2009.

EGBERTO, o Iํㄴ. Leja, ed. 36, I4 mai. I969.

GISMONTI, E. Egberto Gismonti. Academia de danças. EMI Odeon, I974. Memória da música brasileira.

Som do Vinil. 20I5. Entrevista concedida a Charles Gavin. Disponível em: <http://osomdovinil.org/ egberto-gismonti-academia-de-dancas-emi-odeon-I976/>. Acesso em: 5 abr. 2016.

GUIGUE, Didier. Estética da sonoridade. São Paulo: Perspectiva, $20 I I$.

. Estética da sonoridade: teoria e prática de um método analítico - uma introdução. Claves, n. 4, p.

37-65. Periódico do Programa de Pós-Graduação em Música da UFPB, nov. 2007.

GUIMARÃES, Márcia. Egberto Gismonti - foi difícil me livrar da música erudita. Última Hora, 30/9/1976. HALL, Stuart. A identidade cultural na pós-modernidade. Io. ed. Rio de Janeiro: DP\&A, 2005.

MOLINA, Sergio Augusto. A composição de música popular cantada: a construção de sonoridades e a montagem dos álbuns no pós-década de I960. Tese (Doutorado em Música). Escola de Comunicações e Artes, Universidade de São Paulo, São Paulo, 20I4. 
MOREIRA, Maria Beatriz Cyrino. Fusões de gêneros e estilos na produção da banda Som Imaginário. Dissertação (Mestrado em Música). Instituto de Artes, Universidade Estadual de Campinas, Campinas, 20II. NAPOLITANO, Marcos. "Seguindo a canção" - engajamento político e indústria cultural na MPB (I959I969). São Paulo: Annablume/Fapesp, 200I.

NAVES, Santuza Cambraia. O violão azul: modernismo e música popular. Rio de Janeiro: Editora Fundação Getúlio Vargas, I998.

. Canção popular no Brasil: a canção crítica. Rio de Janeiro: Civilização Brasileira, 2010.

NETTO, Michel Nicolau. Música brasileira e identidade nacional na mundialização. São Paulo: Annablume/ Fapesp, 2009.

PENTEADO, Regina. Gismonti, ponto de encontro de vários extremos. Folha de S. Paulo, Ilustrada, 6/9/1975. SOUZA, Tárik de. Do parto erudito à criação coletiva. Jornal do Brasil, Caderno B, p. 5, 9 jun. I976.

TINÉ, Paulo José de Siqueira; PATREZE JUNIOR, Mario A. Procedimentos modais presentes no violão da peça “Cego Aderaldo" de Egberto Gismonti. In: CONGRESSO DA ASSOCIAÇÃO NACIONAL DE PESQUISA E PÓS-GRADUAÇÃO EM MÚSICA - ANPPOM, 25., 20I5, Vitória. Anais... Vitória: Universidade Federal do Espírito Santo, 2015.

UM MÚSICO, enfim, entendido. Folha de S. Paulo, Ilustrada, 5 jun. I976, p. 26. 